\title{
Modeling and simulation of wetted porous thermal barriers operating under high temperature or high heat flux
}

\author{
V.A.F. Costa ${ }^{a, *}$, M.L. Mendonça ${ }^{b}$, A.R. Figueiredo ${ }^{c}$ \\ ${ }^{a}$ Departamento de Engenharia Mecânica, Universidade de Aveiro, Campus Universitário de Santiago, 3810-193 Aveiro, Portugal \\ ${ }^{\mathrm{b}}$ Escola Superior de Tecnologia e Gestão de Águeda, Universidade de Aveiro, Zona Industrial da Alagoa, Apartado 473, 3754-909 Águeda, Portugal \\ ${ }^{\mathrm{c}}$ Departamento de Engenharia Mecânica, Universidade de Coimbra, Pólo II, Pinhal de Marrocos, 3030-201 Coimbra, Portugal
}

Received 20 February 2006

Available online 14 January 2008

\begin{abstract}
Porous media with high water content can be successfully used as thermal barriers to operate under high exposure temperatures and/ or high heat fluxes. Modeling and simulation of such systems presents difficulties and challenges, which are pointed and worked out in this work. Liquid water and water vapor transfers are considered, including the capillary effects for the liquid phase, as well as the air transfer inside the porous medium. Heat transfer model includes conduction, radiation, enthalpy convection, sensible heating and phase change. A realistic model is considered at the exposed boundary in what concerns mass transfer: the outflow mass transfer is dictated by the water effusion and not by the convection transfer mechanism between the exposed surface and the environment. A set of numerical aspects is detailed, concerning both the numerical modeling and the solution of the discretization equations, which are crucial to obtain successful simulations. Some illustrative results are presented, showing the potential of the wetted porous media when used as thermal barriers, as well as the capabilities of the presented physical and numerical models to deal with such systems.
\end{abstract}

(C) 2007 Elsevier Ltd. All rights reserved.

\section{Introduction}

Wetted porous media are very interesting alternatives when searching for thermal barriers to operate under high temperatures or/and high heat fluxes. The high thermal load induces the boiling of the liquid contained inside the porous medium, this phase change acting like a strong heat sink. In this way, the barrier temperature and especially at the face opposed to the exposed one can be maintained within acceptable levels, even if the thermal load and temperature at the exposed surface are very high. This type of thermal barriers can be very useful as protections for firefighters and equipments in forest fires, where very intense thermal loads can be reached but only during relatively short time periods. In this particular case, the initial water content of the barrier can be enough to give it the desirable protection effect. This kind of barriers can also be used to

\footnotetext{
${ }^{*}$ Corresponding author.

E-mail address: v_costa@ua.pt (V.A.F. Costa).
}

protect equipments or structural elements of buildings. As, in general, the thermal load acts during longer times in this case, a feeding process with liquid water is needed and it can be included at the design and construction phases of the equipments or structures. In this case, intense thermal loads can be imposed by particular (expected) operating conditions of some equipments and/or processes, or by unexpected situations like fire exposure.

The use of wet porous media acting as thermal barriers has been the subject of a number of works that can be found in the literature. Examples include the injection of gases in the direction of the exposed surface, and even the injection of a dissociating gas [1,2], in order to increase the heat sink effect of the thermal barrier. Blowing is also considered in the thermal protection analyzed in [3]. Direct exposure to fire has been taken into account in some other works, including the modeling and simulation of firefighter protective clothing during flash fire exposure [4]. Other studies concerning the use of thermal protections under fire conditions can be found [5-10], some of them 


\begin{tabular}{|c|c|c|c|}
\hline \multicolumn{4}{|c|}{ Nomenclature } \\
\hline$c$ & specific heat & $\sigma$ & surface tension \\
\hline$c_{\mathrm{P}}$ & constant pressure specific heat & $\sigma$ & Stefan-Boltzmann constant \\
\hline$D$ & mass diffusion coefficient & $\tau$ & transmissivity of the porous medium \\
\hline$f_{\sigma}$ & factor in the Leverett function & $\tau$ & tortuosity \\
\hline$g$ & gravitational acceleration & & \\
\hline$h$ & specific enthalpy & \multicolumn{2}{|c|}{ Subscripts } \\
\hline$h$ & convection heat transfer coefficient & $\mathrm{a}$ & air \\
\hline$J$ & Jacobian matrix & atm & atmospheric value \\
\hline$k$ & relative permeability & $\mathrm{b}$ & boundary \\
\hline$k$ & thermal conductivity & $\mathrm{c}$ & capillary \\
\hline$K$ & intrinsic permeability & $\mathrm{D}$ & diffusion \\
\hline$L$ & thickness of the porous medium & e & exterior side \\
\hline$m$ & mass & f & formation \\
\hline$P$ & pressure & $\mathrm{g}$ & gas \\
\hline$\dot{Q}^{\prime \prime}$ & heat flux & $\mathrm{i}$ & interior side \\
\hline$R$ & ideal gas particular constant & 1 & liquid \\
\hline$S$ & saturation & lv & liquid-vapor phase change \\
\hline$t$ & time & $m, n$ & indices of the Jacobian matrix \\
\hline$T$ & temperature & $N$ & total number of dependent variables \\
\hline$u$ & velocity & $\mathrm{P}$ & at node $\mathrm{P}$ \\
\hline$v$ & dependent variable (generic) & $\mathrm{r}$ & radiation \\
\hline$V$ & volume & $\mathrm{r}$ & relative \\
\hline$x$ & linear coordinate & $\mathrm{s}$ & radiation shield \\
\hline \multirow[t]{2}{*}{$X$} & moisture content (dry basis) & $\mathrm{S}$ & solid \\
\hline & & sat & saturation conditions \\
\hline \multicolumn{2}{|c|}{ Greek symbols } & $\mathrm{v}$ & vapor \\
\hline$\Delta$ & difference value & 0 & reference value \\
\hline$\varepsilon$ & emissivity & $\infty$ & far from the surface, in the gas \\
\hline$\varepsilon$ & porosity & & \\
\hline$\mu$ & dynamic viscosity & \multicolumn{2}{|c|}{ Superscript } \\
\hline$\gamma$ & extinction coefficient & 0 & reference value (for enthalpy) \\
\hline$\rho$ & density & & \\
\hline
\end{tabular}

characterizing the details of the layered medium, which can include a inside air gap, and thermal radiation heat transfer. Some other studies, just to cite a few, are devoted primarily to questions related to the skin injury $[4,11]$ or to the degradation of the involved materials as well as to the heat and mass transfer aspects of the barriers exposed to fire [12-19]. Special attention has been given to concrete behavior and the possibility of its damage under intense thermal conditions, and in particular under fire conditions [20-25]. In this case, high temperatures give rise to high pressures at the interior, and concrete can fail due to spalling. In what concerns the study of the heat and mass transfer problems in porous and fibrous materials under intense thermal loadings, some studies can be found [16,26-29]. However, in the referred studies, no special attention is paid to the boiling phenomenon taking place inside the porous medium, which plays a fundamental role in the thermal barrier effect under analysis. Some studies dealing with modeling and simulation of boiling in porous media can be found [30-34], but they are not of direct application in the present case as the temperature at which phase change takes place varies with the local vapor pressure.

Many works deal with modeling of heat and mass transfer in porous media [23,24,35-40]. However, invariably, when particular situations are worked out, a phase change by evaporation (a slow phenomenon) is considered inside the porous medium and the generated vapor is supposed to be evacuated from the exposed surface through the convection mechanism. If inside the porous medium vaporization process takes place, the amount of vapor generated is mainly conditioned by the heat transfer reaching the vaporization front, and the expulsion of water is mainly conditioned by the increase in the interior pressure due to vapor formation. The porous barrier behaves like a vessel under pressure, whose vapor outflow is not conditioned by the external convection conditions. The convection mechanism is responsible for heat transfer on the external surface, but it is not of importance for water vapor expulsion (effusion) from the exposed surface. To the authors' knowledge, this is the first time this realistic boundary 
condition for mass transfer is considered, and it has been demonstrated by the preliminary experimental work of Figueiredo and Costa [41].

The thermal barrier analyzed in present work consists of a thin one-dimensional porous medium, initially with a high liquid moisture content, which has a surface exposed to an intense thermal solicitation. The opposite surface is assumed to be impermeable and adiabatic. A perforated thin metallic sheet, with a low emissivity factor, which allows water expulsion but inhibits radiation heat transfer gain from the environment, covers the external surface of the thermal barrier. The main results to be obtained concern the transient internal fields of local water content and temperature. For a wet porous medium of high permeability, like some usual fibrous media, an internal pressure close to the atmospheric pressure is expected (the total pressure at the exposed surface), and thus a temperature close to $100^{\circ} \mathrm{C}$ is expected where liquid-vapor phase change is taking place. Some modeling and numerical aspects are highlighted. In particular, some subtle aspects which are crucial for successful calculations are detailed in this work. Illustrative examples are presented concerning the behavior of a thin thermal protection consisting of glass fiber initially saturated with water.

\section{Physical modeling}

\subsection{Wet porous medium characterization}

The porous medium is characterized through its intrinsic permeability and porosity, both assumed to be constant. No close relationship exists between porosity and the intrinsic permeability, as they are obtained following independent ways. In the porous medium a solid phase exists (the solid porous matrix), and it can exist a liquid phase and a gaseous phase, the latter being a mixture of water vapor and completely dry air, as illustrated in Fig. 1. In this figure, the porous medium is represented, for convenience, as a layered medium with separated phases, even if, in reality, the different phases co-exist in volume.

The porosity of the porous medium is obtained as

$\left.\varepsilon=\frac{V_{\mathrm{g}}+V_{1}}{V} \quad \varepsilon \in\right] 0 ; 1[$

where $V_{\mathrm{g}}+V_{1}$ is the void volume of the porous medium, not occupied by the solid phase. Porosity is defined locally,

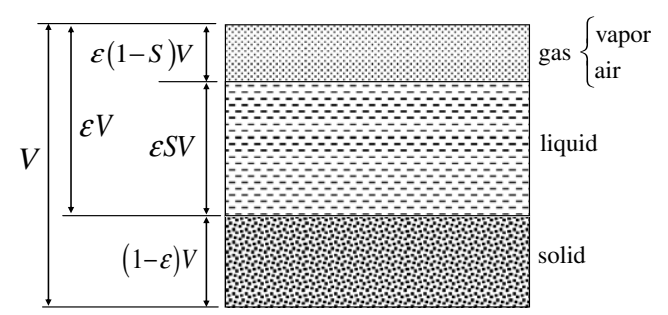

Fig. 1. The porous medium, presented for convenience as a layered medium. but it is assumed to be uniform and constant through the whole porous medium. In this way, the volume occupied by the solid matrix is obtained as $V_{\mathrm{s}}=(1-\varepsilon) V$.

The liquid water content of the porous medium, which is a local variable, can be defined using two different ways. One is through the saturation of the porous medium with liquid, the saturation being defined as the ratio between the actual and the maximum volume that can be occupied by water, when the porous medium is completely saturated with liquid, that is,

$S=\frac{V_{1}}{V_{\mathrm{g}}+V_{1}} \quad S \in[0 ; 1]$

If $S=1$ the porous medium is locally completely saturated with liquid, and if $S=0$ local humidity can exist in the porous medium in the vapor phase only. Another way to define the liquid water content of the porous medium is through the liquid humidity content, usually defined in a dry basis, as the following mass ratio:

$X=\frac{m_{1}}{m_{\mathrm{s}}}=\frac{\rho_{1} \varepsilon S}{\rho_{\mathrm{s}}(1-\varepsilon)}$

In this definition, it is assumed that the vapor present in the porous medium contributes only marginally to the local humidity content. In the context of the present work, the saturation will be used to describe the local liquid content of the porous medium.

It is also assumed that the liquid humidity exists inside the porous medium as unbound liquid only, and thus no complementary information is needed, in the form of sorption isotherms. As a consequence, no heat of sorption will be taken into account. In reality, some very small fraction of the liquid water can be bound water, but it will be of minor relevance for the problem under analysis. In this way, above the saturation temperature for a given pressure inside the porous medium, no humidity exists bounded to the solid phase and the vapor content of the gaseous mixture is an independent variable.

\subsection{Constitutive laws and state equations}

Mass and heat transfer in the porous medium are described using the mass and energy conservation principles, and particular information is needed in order to characterize the way as the particular involved media participate in the transport phenomena. These are given in the form of constitutive laws and/or state equations.

Liquid phase can be transferred in a bulk way, as an advective flux only. Velocity corresponding to this bulk transfer is obtained using the generalized Darcy Law as [35]

$u_{1}=-\frac{K k_{\mathrm{r} 1}}{\mu_{1}}\left(\frac{\partial P_{1}}{\partial x}+\rho_{1} g\right)$

where $K$ is the intrinsic permeability of the porous medium and $k_{\mathrm{rl}}$ is the relative permeability of the liquid. The gaseous phase can be equally transferred in a bulk way, the velocity corresponding to the bulk motion of the gaseous 
phase being obtained using again the generalized Darcy Law to give [35]

$u_{\mathrm{g}}=-\frac{K k_{\mathrm{rg}}}{\mu_{\mathrm{g}}}\left(\frac{\partial P_{\mathrm{g}}}{\partial x}+\rho_{\mathrm{g}} g\right)$

where $k_{\mathrm{rg}}$ is the relative permeability of the gas phase. The relative permeabilities $k_{\mathrm{rl}}$ and $k_{\mathrm{rg}}$ are obtained as functions of the saturation $S$. In this work, they are evaluated as [39]

$k_{\mathrm{rl}}=S^{3} \quad k_{\mathrm{rl}} \in[0 ; 1]$

$k_{\mathrm{rg}}=1+(2 S-3) S^{2} \quad k_{\mathrm{rg}} \in[0 ; 1]$

The pressure of the liquid phase and that of the gaseous phase are related through the capillary depression, with

$P_{1}=P_{\mathrm{g}}-\Delta P_{\mathrm{c}}$

where the capillary depression $\Delta P_{\mathrm{c}}$ depends of the involved media, and of the saturation of the porous medium with liquid. In this work, it is evaluated using the Leverett function as [36]

$$
\begin{aligned}
\Delta P_{\mathrm{c}}= & f_{\sigma} \sqrt{\frac{\varepsilon}{K}} \sigma(1-S)\{1.417+(1-S)[-2.12 \\
& +1.263(1-S)]\}
\end{aligned}
$$

When dealing with porous media with high permeability, the liquid pressure differences can be strongly conditioned by capillarity and not by the permeability of the medium. In order to avoid the dominance of the capillarity effects for high permeability porous media, as is the present case, it is introduced the additional dimensionless factor $f_{\sigma}$ in Eq. (9), which needs to be tuned in order to have a correct account of both the permeability and capillarity effects.

Before analyzing the transport phenomena of the gaseous phase, and of each particular component, it remains to be clarified the way as its vapor and air contents are defined. The vapor content of the gaseous phase is defined through the intrinsic density

$\rho_{\mathrm{v}}^{\prime}=\frac{m_{\mathrm{v}}}{V_{\mathrm{g}}}$

where it must be stressed that $\rho_{\mathrm{v}}^{\prime} \neq \rho_{\mathrm{v}}$ as volume $V_{\mathrm{g}}$ is filled with a two-component mixture of dry air and vapor and not only with vapor. By similar reasons, the air content of the gaseous mixture is defined through the intrinsic density

$\rho_{\mathrm{a}}^{\prime}=\frac{m_{\mathrm{a}}}{V_{\mathrm{g}}}$

where $\rho_{\mathrm{a}}^{\prime} \neq \rho_{\mathrm{a}}$ by the same reasons.

Each component of the gaseous mixture has a bulk motion, with velocity $u_{\mathrm{g}}$ given by Eq. (5) but, as the concentration of each component is non-uniform in the gaseous mixture, there is a diffusive transport of each component, described by the Fick's Law. The diffusive fluxes of vapor and air in the gaseous mixture are obtained respectively as [42]
$\rho_{\mathrm{g}}\left(u_{\mathrm{v}}\right)_{\mathrm{D}}=-\rho_{\mathrm{g}} \frac{D}{\tau} k_{\mathrm{rg}} \frac{\partial}{\partial x}\left(\frac{\rho_{\mathrm{v}}^{\prime}}{\rho_{\mathrm{g}}}\right)$
$\rho_{\mathrm{g}}\left(u_{\mathrm{a}}\right)_{\mathrm{D}}=-\rho_{\mathrm{g}} \frac{D}{\tau} k_{\mathrm{rg}} \frac{\partial}{\partial x}\left(\frac{\rho_{\mathrm{a}}^{\prime}}{\rho_{\mathrm{g}}}\right)$

As the diffusive path in the porous medium is higher than in a clear fluid the effective diffusion coefficient in Eqs. (12) and (13) is defined as $D / \tau$, where $\tau$ is the tortuosity factor [36]. Due to the presence of the liquid phase, the available cross-section for the diffusive transfer in the gaseous phase is only a fraction of the maximum available crosssection, this fraction being taken as the relative permeability of the gaseous phase, $k_{\mathrm{rg}}$. For the gaseous mixture it is $\rho_{\mathrm{g}}=\rho_{\mathrm{a}}^{\prime}+\rho_{\mathrm{v}}^{\prime}$ and it can be obtained from Eqs. (12) and (13) that $\left(u_{\mathrm{a}}\right)_{\mathrm{D}}=-\left(u_{v}\right)_{\mathrm{D}}$, a well-known result for the equimolar counter-diffusion situation [42].

Each component of the gaseous mixture is assumed to behave as an ideal gas, the same occurring with the gaseous mixture, and the following relationships apply:

$P_{\mathrm{v}}=\rho_{\mathrm{v}}^{\prime} R_{\mathrm{v}} T$

$P_{\mathrm{a}}=\rho_{\mathrm{a}}^{\prime} R_{\mathrm{a}} T$

$P_{\mathrm{g}}=P_{\mathrm{a}}+P_{\mathrm{v}}=\left(\rho_{\mathrm{a}}^{\prime} R_{\mathrm{a}}+\rho_{\mathrm{v}}^{\prime} R_{\mathrm{v}}\right) T$

$\rho_{\mathrm{g}}=\rho_{\mathrm{a}}^{\prime}+\rho_{\mathrm{v}}^{\prime}$

$P_{\mathrm{v}}$ and $P_{\mathrm{a}}$ being the partial pressures of water vapor and air in the gaseous phase, respectively.

Energy is transferred in the porous medium both in a bulk way (advection) and by conduction. The enthalpy terms in the energy conservation equation are treated assuming that, for the present purposes, the enthalpy of each particular species present can be evaluated as

$h_{\mathrm{s}}=h_{\mathrm{fs}}^{0}+c_{\mathrm{s}}\left(T-T_{0}\right)$

$h_{1}=h_{\mathrm{fl}}^{0}+c_{1}\left(T-T_{0}\right)$

$h_{\mathrm{v}}=h_{\mathrm{fl}}^{0}+h_{\mathrm{lv}}^{0}+c_{\mathrm{Pv}}\left(T-T_{0}\right)$

$h_{\mathrm{a}}=h_{\mathrm{fa}}^{0}+c_{\mathrm{Pa}}\left(T-T_{0}\right)$

with constant specific heats $c_{\mathrm{s}}, c_{1}, c_{\mathrm{Pv}}$ and $c_{\mathrm{Pa}}$. It is assumed that, locally, all the involved components share the same temperature, that is, it is assumed local thermal equilibrium. Heat transfer by conduction is described by the Fourier's Law, the local thermal conductivity being obtained as the volume averaged value of the thermal conductivities of the involved media as

$$
\begin{aligned}
k_{m} & =\frac{k_{\mathrm{s}} V_{\mathrm{s}}+k_{1} V_{1}+k_{\mathrm{g}} V_{\mathrm{g}}}{V_{\mathrm{s}}+V_{1}+V_{\mathrm{g}}} \\
& =(1-\varepsilon) k_{\mathrm{s}}+\varepsilon\left[S k_{1}+(1-S) \frac{\left(\rho_{\mathrm{v}}^{\prime} k_{\mathrm{v}}+\rho_{\mathrm{a}}^{\prime} k_{\mathrm{a}}\right)}{\rho_{\mathrm{v}}^{\prime}+\rho_{\mathrm{a}}^{\prime}}\right]
\end{aligned}
$$

where the thermal conductivity of the gaseous mixture has been obtained as the mass averaged value of the thermal conductivities of its components.

When, locally, some liquid exists, it is assumed that the existing vapor in the gaseous phase is in the saturation 
conditions, the saturation pressure being evaluated as a function of temperature through the correlation [43]

$$
\begin{aligned}
P_{\text {sat }}(T)= & \exp \left[72.1511-\frac{7089.3840}{T}-7.3020 \ln (T)\right. \\
& +0.0043 T][\mathrm{Pa}]
\end{aligned}
$$

with temperature $T$ in the absolute Kelvin scale.

\subsection{Radiation model}

The adopted radiation model is essentially the one developed and used in $[4,16,44,45]$, where the porous medium includes liquid water. A different approach, using the two-flux model of radiation has been followed in [1,2], where the gas that saturates the porous medium is a transparent gas.

Heat flux received by the radiation shield from the hot gas is $\varepsilon_{\mathrm{g}} \sigma T_{\mathrm{g}}^{4}$, whereas the radiation shield reflects part of this incident radiation flux evaluated as $\rho_{\mathrm{s}, \mathrm{e}} \varepsilon_{\mathrm{g}} \sigma T_{\mathrm{g}}^{4}=$ $\left(1-\varepsilon_{\mathrm{s}, \mathrm{e}}\right) \varepsilon_{\mathrm{g}} \sigma T_{\mathrm{g}}^{4}$ and emits flux radiation both in the hot gas direction as $\varepsilon_{\mathrm{s}, \mathrm{e}} \sigma T_{\mathrm{s}}^{4}$ and in the porous medium direction as $\varepsilon_{\mathrm{s}, \mathrm{i}} \sigma T_{\mathrm{s}}^{4}$, as depicted in Fig. 2. In this way, the net radiation heat flux received by the radiation shield is

$\dot{Q}_{\mathrm{r}, \mathrm{s}}^{\prime \prime}=\sigma\left[\varepsilon_{\mathrm{s}, \mathrm{e}} \varepsilon_{\mathrm{g}} T_{\mathrm{g}}^{4}-\left(\varepsilon_{\mathrm{s}, \mathrm{e}}+\varepsilon_{\mathrm{s}, \mathrm{i}}\right) T_{\mathrm{s}}^{4}\right]$

where $\varepsilon_{\mathrm{s}, \mathrm{e}}$ and $\varepsilon_{\mathrm{s}, \mathrm{i}}$ are the emissivities of the exterior and interior sides of the radiation shield, respectively. This term is to be included as an energy input for the exposed boundary control-volume.

The heat flux radiated from the interior side of the shield in the direction of the porous medium

$\dot{Q}_{\mathrm{r}, 0}^{\prime \prime}=\varepsilon_{\mathrm{s}, \mathrm{i}} \sigma T_{\mathrm{s}}^{4}$

is attenuated as it penetrates in the porous medium and the intensity of radiant heat transfer at any location of the porous medium is obtained as

$\dot{Q}_{\mathrm{r}}^{\prime \prime}=\dot{Q}_{\mathrm{r}, 0}^{\prime \prime} \mathrm{e}^{-\gamma x}$

where $x$ is the distance measured away from the exposed boundary, and

$\gamma=\frac{-\ln \tau}{L}$

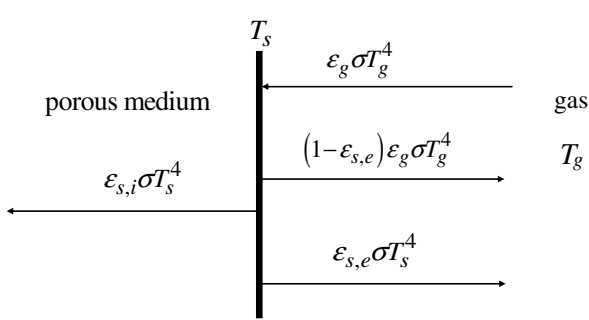

Fig. 2. Radiation fluxes at the surface.
In the last equation $\tau$ is the radiation transmissivity of the porous medium and $L$ is its thickness.

This model assumes that radiation is absorbed once it contacts the solid fibers, and thus the in-depth penetration of radiation is only a function of the internal geometry of the porous matrix. Absorption of radiation by the liquid water is negligible when compared with the radiation absorption by the solid fibers. Results obtained with such a model agree very well with those given by the Beer's Law, with transmissivities close to 0.01 [44].

The radiation energy term present in the energy conservation equation, including radiation heat transfer, is evaluated as

$-\frac{\partial \dot{Q}_{\mathrm{r}}^{\prime \prime}}{\partial x}=\gamma \dot{Q}_{\mathrm{r}, 0}^{\prime \prime} \mathrm{e}^{-\gamma x}$

which enters the energy conservation equation as (positive) energy source term, as result of the attenuation of the radiation heat flux as it crosses the porous medium.

\subsection{Governing equations}

The governing equations are obtained by setting the mass and energy conservation principles for air, water and energy. The air mass conservation equation gives

$\frac{\partial}{\partial t}\left[\rho_{\mathrm{a}}^{\prime} \varepsilon(1-S)\right]+\frac{\partial}{\partial x}\left[\rho_{\mathrm{a}}^{\prime} u_{\mathrm{g}}+\rho_{\mathrm{g}}\left(u_{\mathrm{a}}\right)_{\mathrm{D}}\right]=0$

the mass conservation equation of water gives

$\frac{\partial}{\partial t}\left[\rho_{1} \varepsilon S+\rho_{\mathrm{v}}^{\prime} \varepsilon(1-S)\right]+\frac{\partial}{\partial x}\left[\rho_{1} u_{1}+\rho_{\mathrm{v}}^{\prime} u_{\mathrm{g}}+\rho_{\mathrm{g}}\left(u_{\mathrm{v}}\right)_{\mathrm{D}}\right]=0$

and the energy conservation equation gives

$$
\begin{aligned}
& \frac{\partial}{\partial t}\left\{\left[\varepsilon \rho_{1} S c_{1}+(1-\varepsilon) \rho_{\mathrm{s}} c_{\mathrm{s}}+\varepsilon(1-S)\left(\rho_{\mathrm{a}}^{\prime} c_{\mathrm{Pa}}+\rho_{\mathrm{v}}^{\prime} c_{\mathrm{Pv}}\right)\right] T\right. \\
& \left.\quad+h_{\mathrm{lv}}^{0}\left[\varepsilon(1-S) \rho_{\mathrm{v}}^{\prime}\right]\right\}+\frac{\partial}{\partial x}\left\{\left[\rho_{\mathrm{l}} u_{1} c_{1}+\left(\rho_{\mathrm{v}}^{\prime} u_{\mathrm{g}}+\rho_{\mathrm{g}}\left(u_{\mathrm{v}}\right)_{\mathrm{D}}\right) c_{\mathrm{Pv}}\right.\right. \\
& \left.\left.\quad+\left(\rho_{\mathrm{a}}^{\prime} u_{\mathrm{g}}+\rho_{\mathrm{g}}\left(u_{\mathrm{a}}\right)_{\mathrm{D}}\right) c_{\mathrm{Pa}}\right] T\right\} \\
& \quad+\frac{\partial}{\partial x}\left\{-k_{m} \frac{\partial T}{\partial x}+h_{\mathrm{lv}}^{0}\left[\rho_{\mathrm{v}}^{\prime} u_{\mathrm{g}}+\rho_{\mathrm{g}}\left(u_{\mathrm{v}}\right)_{\mathrm{D}}\right]\right\}-\gamma \dot{Q}_{\mathrm{r}, 0}^{\prime \prime} \mathrm{e}^{-\gamma x}=0
\end{aligned}
$$

Eq. (23) is used to obtain the local air content of the gaseous mixture, $\rho_{\mathrm{a}}^{\prime}$, and Eq. (24) is used to obtain the local liquid saturation, $S$, or the local vapor content of the gaseous mixture, $\rho_{\mathrm{v}}^{\prime}$. If $S>0$, locally liquid exists in the porous medium, and vapor existing in the gaseous mixture is in local saturation conditions, the local vapor content of the gaseous mixture being evaluated as depending on temperature through

$\rho_{\mathrm{v}}^{\prime}=\frac{P_{\mathrm{sat}}(T)}{R_{\mathrm{v}} T}$

and Eq. (24) is used to obtain the saturation $S$. If, instead, locally it is $S=0$, the local vapor content of the gaseous 
mixture is an independent variable that cannot be evaluated from Eq. (26), and it is evaluated from Eq. (24). By its own turn, Eq. (25) is used to obtain the local temperature.

\subsection{Boundary conditions}

The external surface of the thermal barrier under study is supposed to be covered with a radiation shield, in order to attenuate the received radiation heat transfer. This radiation shield is perforated, with many small diameter holes, allowing the exit of the moisture contained in the porous medium. In this way, the thermal barrier receives heat by convection from the exterior stream of hot gas, with a high convection heat transfer coefficient. However, no convection mass transfer takes place at the exposed boundary, and the moisture contained in the porous medium is expulsed due to the pressure increase inside the porous medium, as its temperature increases and liquid humidity boils.

For the air mass conservation equation the boundary condition at the exposed surface is then

$\left[\rho_{\mathrm{a}}^{\prime} u_{\mathrm{g}}+\rho_{\mathrm{g}}\left(u_{\mathrm{a}}\right)_{\mathrm{D}}\right]_{\mathrm{b}}=\left(\rho_{\mathrm{a}}^{\prime} u_{\mathrm{g}}\right)_{\mathrm{b}}$

For the mass conservation equation of water the boundary condition at the exposed surface is

$\left[\rho_{1} u_{1}+\rho_{\mathrm{v}}^{\prime} u_{\mathrm{g}}+\rho_{\mathrm{g}}\left(u_{\mathrm{v}}\right)_{\mathrm{D}}\right]_{\mathrm{b}}=\left[\rho_{1} \max \left(u_{1}, 0\right)+\rho_{\mathrm{v}}^{\prime} u_{\mathrm{g}}\right]_{\mathrm{b}}$

noting that liquid water can leave the porous medium through the exposed boundary, due to local differences in the liquid pressure, but that liquid cannot enter the porous medium (from the outer gaseous stream) through that boundary. In what concerns the boundary condition for the energy conservation equation, it must include the heat gain by convection and radiation from the exterior hot stream, and also the enthalpy terms associated with the liquid and gaseous currents there, and it becomes

$$
\begin{aligned}
& \left\{\begin{array}{l}
{\left[\rho_{1} u_{1} c_{1}+\left(\rho_{\mathrm{v}}^{\prime} u_{\mathrm{g}}+\rho_{\mathrm{g}}\left(u_{\mathrm{v}}\right)_{\mathrm{D}}\right) c_{\mathrm{Pv}}+\left(\rho_{\mathrm{a}}^{\prime} u_{\mathrm{g}}+\rho_{\mathrm{g}}\left(u_{\mathrm{a}}\right)_{\mathrm{D}}\right) c_{\mathrm{Pa}}\right] T} \\
-k_{m} \frac{\partial T}{\partial x}+h_{\mathrm{lv}}^{0}\left[\rho_{\mathrm{v}}^{\prime} u_{\mathrm{g}}+\rho_{\mathrm{g}}\left(u_{\mathrm{v}}\right)_{\mathrm{D}}\right]
\end{array}\right\}_{\mathrm{b}} \\
& =\left\{\begin{array}{c}
{\left[\rho_{1} c_{1} \max \left(u_{1}, 0\right)+\rho_{\mathrm{v}}^{\prime} u_{\mathrm{g}} c_{\mathrm{Pv}}+\rho_{\mathrm{a}}^{\prime} u_{\mathrm{g}} c_{\mathrm{Pa}}\right] T} \\
+h_{\mathrm{lv}}^{0} \rho_{\mathrm{v}}^{\prime} u_{\mathrm{g}}+h\left(T-T_{\infty}\right) \\
-\sigma\left[\varepsilon_{\mathrm{s}, \mathrm{e}} \varepsilon_{\mathrm{g}} T_{\mathrm{g}}^{4}-\left(\varepsilon_{\mathrm{s}, \mathrm{e}}+\varepsilon_{\mathrm{s}, \mathrm{i}}\right) T_{\mathrm{s}}^{4}\right]
\end{array}\right\}_{\mathrm{b}}
\end{aligned}
$$

The surface opposed to the exposed one is assumed to be impermeable both to air and water, and it is assumed to be adiabatic. On that surface the boundary condition for the air mass conservation equation is thus

$\left[\rho_{\mathrm{a}}^{\prime} u_{\mathrm{g}}+\rho_{\mathrm{g}}\left(u_{\mathrm{a}}\right)_{\mathrm{D}}\right]_{\mathrm{b}}=0$

the boundary condition for the water mass conservation equation is

$\left[\rho_{\mathrm{l}} u_{1}+\rho_{\mathrm{v}}^{\prime} u_{\mathrm{g}}+\rho_{\mathrm{g}}\left(u_{\mathrm{v}}\right)_{\mathrm{D}}\right]_{\mathrm{b}}=0$ and the boundary condition for the energy conservation equation gives

$\left\{\begin{array}{l}{\left[\rho_{\mathrm{l}} u_{\mathrm{l}} c_{1}+\left(\rho_{\mathrm{v}}^{\prime} u_{\mathrm{g}}+\rho_{\mathrm{g}}\left(u_{\mathrm{v}}\right)_{\mathrm{D}}\right) c_{\mathrm{Pv}}+\left(\rho_{\mathrm{a}}^{\prime} u_{\mathrm{g}}+\rho_{\mathrm{g}}\left(u_{\mathrm{a}}\right)_{\mathrm{D}}\right) c_{\mathrm{Pa}}\right] T} \\ -k_{m} \frac{\partial T}{\partial x}+h_{\mathrm{lv}}^{0}\left[\rho_{\mathrm{v}}^{\prime} u_{\mathrm{g}}+\rho_{\mathrm{g}}\left(u_{\mathrm{v}}\right)_{\mathrm{D}}\right]\end{array}\right\}_{\mathrm{b}}=0$

\section{Numerical modeling}

The presented physical model is solved using a controlvolume approach to obtain the discretization equations [46], and the Newton method to obtain the solution of the so obtained non-linear and strongly linked discretization equations.

When dealing with this kind of problems variables are strongly linked, the involved equations are strongly nonlinear, and segregated methods of solution usually fail. For porous media of high permeability, small temperature changes lead to considerable pressure and velocity changes and the segregated methods are not indicated to deal with the so linked variables. The energy conservation equation is dominated by the latent heat of vaporization, and small changes in composition can lead to strong changes in temperature, and cause the failure of the overall numerical method. This can be overwhelmed by using a method capable of obtaining the simultaneous solution of all the involved variables over the whole domain. The Newton method is the most adequate one to deal with non-linear equations, as it directs, simultaneously, all the involved variables towards the solution.

There are four variables to be evaluated at each node, namely saturation $S$, temperature $T$, and the vapor and air contents of the gaseous mixture, $\rho_{\mathrm{v}}^{\prime}$ and $\rho_{\mathrm{a}}^{\prime}$, respectively. If, locally, $S>0, \rho_{\mathrm{v}}^{\prime}$ is directly evaluated from Eq. (26). On the other hand, if $S=0, \rho_{\mathrm{v}}^{\prime}$ is locally evaluated as the solution of the differential equation expressing the mass conservation of water, Eq. (24). In the analysis of drying processes usually only three independent variables exist to be evaluated at each node, namely saturation, temperature and the air content of the gaseous mixture [37-39]. The vapor content of the gaseous mixture is determined once known the saturation and the temperature, through a sorption isotherm. It is to be retained, however, that the sorption isotherm concept makes sense only if bound water exists, and that it makes no sense for temperatures considerably higher than that corresponding to the boiling point of water.

The numerical mesh must be carefully selected, taking into account some particularities of the involved phenomena. If the first node on the side of the exposed surface is placed over it, pressure $P_{\mathrm{g}}$ at such a node is the atmospheric pressure and no pressure difference exists to cause the vapor expulsion. The liquid at such a node can reach temperatures higher than the saturation temperature for the prevailing total pressure, without boiling and vapor expulsion, a clearly non-realistic situation. This can be 


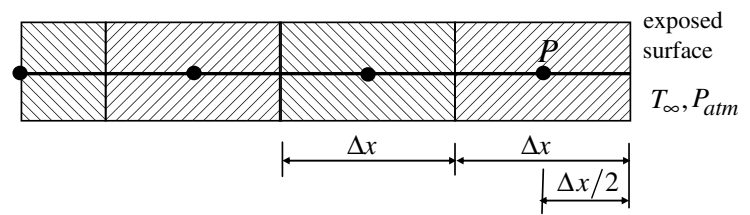

Fig. 3. Used mesh, with emphasis at the exposed surface.

overwhelmed considering a mesh like presented in Fig. 3. Temperature, saturation, $\rho_{\mathrm{a}}^{\prime}$ and $\rho_{\mathrm{v}}^{\prime}$ are evaluated at the nodes. However, to have the outflow boundary conditions for the water and air mass conservation equations, and for the energy conservation equation, as specified by the boundary conditions at the exposed surface, the surface liquid and gas velocities at the exposed surface are evaluated as

$$
\begin{aligned}
& u_{1} \approx-\frac{K k_{\mathrm{r} l \mathrm{P}}}{\mu_{1, \mathrm{P}}}\left[\frac{P_{1, \mathrm{P}}-\left(P_{\mathrm{atm}}-\Delta P_{\mathrm{c}, \mathrm{P}}\right)}{\Delta x / 2}+\rho_{1, \mathrm{P}} g\right] \\
& u_{\mathrm{g}} \approx-\frac{K k_{\mathrm{rg}, \mathrm{P}}}{\mu_{\mathrm{g}, \mathrm{P}}}\left(\frac{P_{\mathrm{g}, \mathrm{P}}-P_{\mathrm{atm}}}{\Delta x / 2}+\rho_{\mathrm{g}, \mathrm{P}} g\right)
\end{aligned}
$$

In this way, if temperature of point $P$ increases, the vapor pressure also increases. If temperature reaches the boiling point, vaporization begins and vapor is generated and, as a consequence, pressure of point $P$ increases and gives rise to positive velocity values $u_{1}$ and $u_{\mathrm{g}}$ at the exposed surface that will be responsible by the humidity and air expulsion from the porous medium to the exterior hot gaseous stream.

Pressure of the liquid phase is evaluated from the pressure of the gaseous phase and from the knowledge of the capillary depression. The developed methodology applies only to porous media that are not completely saturated with liquid water but have, at the least, a small amount of gaseous mixture. In the present work, the highest saturation value is $S=0.99$, which corresponds very closely to a porous medium completely saturated with liquid water. Conceptually, if the porous medium is completely saturated with liquid water, the mass conservation equation of the (liquid) water will result in a Poisson equation whose solution gives the pressure of the liquid (the unique fluid present, in such a case) [35].

The air mass conservation equation can be used to obtain the pressure of the gaseous phase, a practice usual in the drying literature [38]. Such practice, however, can lead to vapor pressures higher than the total pressure, and thus to non-realistic negative partial pressures of air, and to negative values of $\rho_{\mathrm{a}}^{\prime} \mathrm{Eq}$. (14). With the practice followed in this work, values for $\rho_{\mathrm{a}}^{\prime}$ and $\rho_{\mathrm{v}}^{\prime}$ are obtained from the respective equations, they are always positive variables, and the pressure of the gaseous phase is obtained from Eq. (14c), thus giving always physically realistic values for the involved variables.

Time discretization is made using a fully implicit scheme. Theoretically, this imposes no restrictions on the used time step [46]. It was found, however, that the strongly non-linear character of the discretization equations, and the presence of the high value of the latent heat of vaporization in the energy conservation equation, requires the use of short time steps for successful calculations.

The main equations governing the problem under analysis are mass and energy conservation equations, and special care needs to be taken in order to respect these conservation principles when obtaining the discretization equations from the differential equations. This can be ensured by using the control-volume method, which guarantees that no artificial sources or sinks of the conserved variables exist, namely at the interface between adjacent control volumes [46]. The main remaining uncertainties are associated to the discrete nature of the discretization equations, both in time and in space, and to the deficient knowledge of the way as the properties of the involved media depend on the main variables. It must be mentioned here that some works concerning drying problems use a non-conservative form of the energy conservation equation $[37,38,21]$, resulting in some inaccuracy as this is the leading equation for this kind of problems.

The convective terms are discretized using the upwind scheme, and the diffusive terms are discretized using a centered scheme [46]. In what concerns the convective scheme used to discretize the energy conservation equation, as there are different mass fluxes with different specific heats on that equation, and eventually with opposite signs, at each control surface it is evaluated the net value of $\dot{m} c=\sum_{i} \dot{m}_{i} c_{i}$, and this net result is the value used in the upwind scheme [46].

The Jacobian matrix, needed to obtain the solution of the discretization equations' system at each time level, is evaluated in a numerical way as its analytical solution is impracticable due to the highly non-linear character of the equations. Its component $J_{m, n}$ is evaluated as

$$
\begin{aligned}
J_{m, n} & =\frac{\partial f_{m}}{\partial v_{n}} \\
& \approx \frac{f_{m}\left(v_{1}, v_{2}, \ldots, v_{n}+\Delta v, \ldots, v_{N}\right)-f_{m}\left(v_{1}, v_{2}, \ldots, v_{n}, \ldots, v_{N}\right)}{\Delta v}
\end{aligned}
$$

Increment $\Delta v$ is selected as giving rise to numerators of Eq. (34) close to the numerical accuracy limit of the machine. This leads to a time consuming process, but it has been found to be the most effective, if not unique, way to obtain the solution of the discretization equations.

As the mass conservation equation of water, Eq. (24), can be used to evaluate the saturation or the vapor content of the gaseous mixture, depending on the value of saturation $S$, care needs to be taken with the used forms of such an equation. If the used form is the same to evaluate $S$ or $\rho_{\mathrm{v}}^{\prime}$, the Jacobian matrix will have similar rows, the inverse of the Jacobian matrix cannot be evaluated, and the discretization equations' system has no solution. A successful practice is to use Eq. (24) with 0 instead of $S$ in the 
unsteady term when this differential equation is used to evaluate the local vapor content of the gaseous mixture, $\rho_{\mathrm{v}}^{\prime}(S=0)$.

Solution is obtained from time level to time level, the liquid water contained in the porous medium boils and is transferred by advection and diffusion towards the exposed surface, where it leaves the porous medium. Heat is transferred by conduction in the opposite sense, from the exposed surface to the interior of the porous medium. When a control-volume reaches a null saturation with liquid the local temperature increases rapidly, the same occurring with the pressure of the gaseous mixture. For some instants there is only a small amount of water leaving the porous medium, and the mass flow rate of water leaving the porous medium is not a monotonic function of time. This can lead to divergence in the calculations if a very short time step is not used when strong changes of variables occur. A variable time step is used for this reason, the shorter time steps corresponding to the situation where a control-volume ceases having liquid water and its local temperature and gaseous pressure rapidly increase.

\section{Illustrative results}

The considered thermal barriers can be made of many different materials. In the present work it is considered the use of a $5 \mathrm{~mm}$ thickness fiberglass thermal barrier. Gravity is not taken into account when evaluating convective velocities as given by Eqs. (4) and (5), and thus the position of the thermal barrier relative to the vertical direction is irrelevant. Intrinsic permeability and porosity of the porous medium depend strongly on the pressure exerted over the porous medium, and they were taken as $K=3 \times 10^{-11} \mathrm{~m}^{2}$ and 0.67 , respectively. Tortuosity factor was taken as $\tau=10$, and the intrinsic thermal conductivity of the fiberglass was taken as $k_{\mathrm{s}}=1.3 \mathrm{~W} \mathrm{~m}^{-1} \mathrm{~K}^{-1}$.

In what concerns the radiative properties, the environment gaseous phase was assumed to have an emissivity $\varepsilon_{\mathrm{g}}=0.02$, a reasonable value for some hot gas streams or even for 'radiatively cold' flames, and the radiation shield was taken with equal properties interior and exterior radiative surfaces, with an emissivity factor $\varepsilon_{\mathrm{s}, \mathrm{i}}=\varepsilon_{\mathrm{s}, \mathrm{e}}=0.1$. The extinction factor of the porous medium for radiation was taken as $\tau=0.01$ [4].

Initially, the porous medium is nearly saturated with liquid water, with $S=0.99$, and at the temperature of $20^{\circ} \mathrm{C}$. The ambient to which it is exposed is maintained at the temperature of $1000{ }^{\circ} \mathrm{C}$, and the convection heat transfer coefficient is $75 \mathrm{~W} \mathrm{~m}^{-2} \mathrm{~K}^{-1}$. For a surface temperature close to $100^{\circ} \mathrm{C}$ this results on a convection heat flux input of $67.5 \mathrm{~kW} \mathrm{~m}^{-2}$, to a radiation heat flux input of $188 \mathrm{~W} \mathrm{~m}^{-2}$, and to a radiation heat flux released by the shield towards the porous medium of $110 \mathrm{~W} \mathrm{~m}^{-2}$. It can thus be concluded that convection heat transfer is the dominant mechanism. The total pressure of the environment gaseous phase is maintained at $P_{\mathrm{atm}}=1.01325 \times 10^{5} \mathrm{~Pa}$, and its humidity is not relevant, as the outflow boundary condition for the water conservation equation does not depend on it.

The used mesh has 41 equally spaced nodes. The time discretization is made using the fully implicit scheme and a non-uniform time step, which is smaller when temperature strongly changes with time.

In Fig. 4 are presented the results for the permeability factor $f_{\sigma}=0.04$. From Fig. $4 \mathrm{a}$ it can be seen that the exposed surface rapidly reaches the saturation temperature of $100{ }^{\circ} \mathrm{C}$, and that this temperature value is maintained at the exposed surface until liquid water exists there. When no more liquid water exists at the exposed surface local temperature begins rising, what happens for a time close to $55 \mathrm{~s}$. The water comes from the interior towards the exposed surface due to the combined mechanisms of convection (liquid, including the capillarity effects, and vapor) and diffusion (vapor). At the middle of the initially saturated porous medium the temperature rise towards the saturation temperature is slower, as heat needs to travel by conduction and radiation from the exposed surface to the middle of the porous medium. The saturation temperature at the middle of the porous medium is close to $100^{\circ} \mathrm{C}$ and the total pressure there is close to the atmospheric pressure, due to its high permeability. Liquid water disappears on the middle of the porous medium closely $90 \mathrm{~s}$ after the exposition begins, and its temperature also begins rising steeply after that. In what concerns the interior surface of the porous medium, its temperature initially increases more slowly, and after closely $55 \mathrm{~s}$ it reaches the saturation temperature. Once again, as the porous medium has a high permeability the total pressure at its interior is close to the atmospheric pressure, and the saturation temperature is close to $100{ }^{\circ} \mathrm{C}$. In fact, the saturation temperature slightly increases as the distance measured away from the exposed surface increases. Its gradient towards the external atmospheric pressure gives rise to the bulk flow towards the exposed surface. If $100^{\circ} \mathrm{C}$ is taken as a temperature limit for safety reasons, the thermal barrier presents, in this case, a time of effective protection of about $115 \mathrm{~s}$. After this period, the porous medium is completely dry, and it can no longer act like a thermal barrier. To analyze the protection efficiency of an initially liquid-saturated porous medium from this point of view, the most relevant information is given by the temperature field, depicted in Fig. 4a.

In Fig. $4 \mathrm{~b}$ is presented the time evolution of the saturation at the exposed surface, at the middle of the porous medium, and at the interior surface of the porous medium. Initially, the saturation at the exposed surface steeply decreases, as some water is expulsed in both vapor and liquid phases, the pressure decrease in the direction of the exposed surface being responsible for the convective fluxes of both water vapor and liquid water. As time increases, higher temperatures are reached at the interior of the porous medium, and after the saturation temperature is reached vaporization of water takes place inside the porous medium, with a rate mainly conditioned by the heat rate reaching the interior of the porous medium. In this way, 

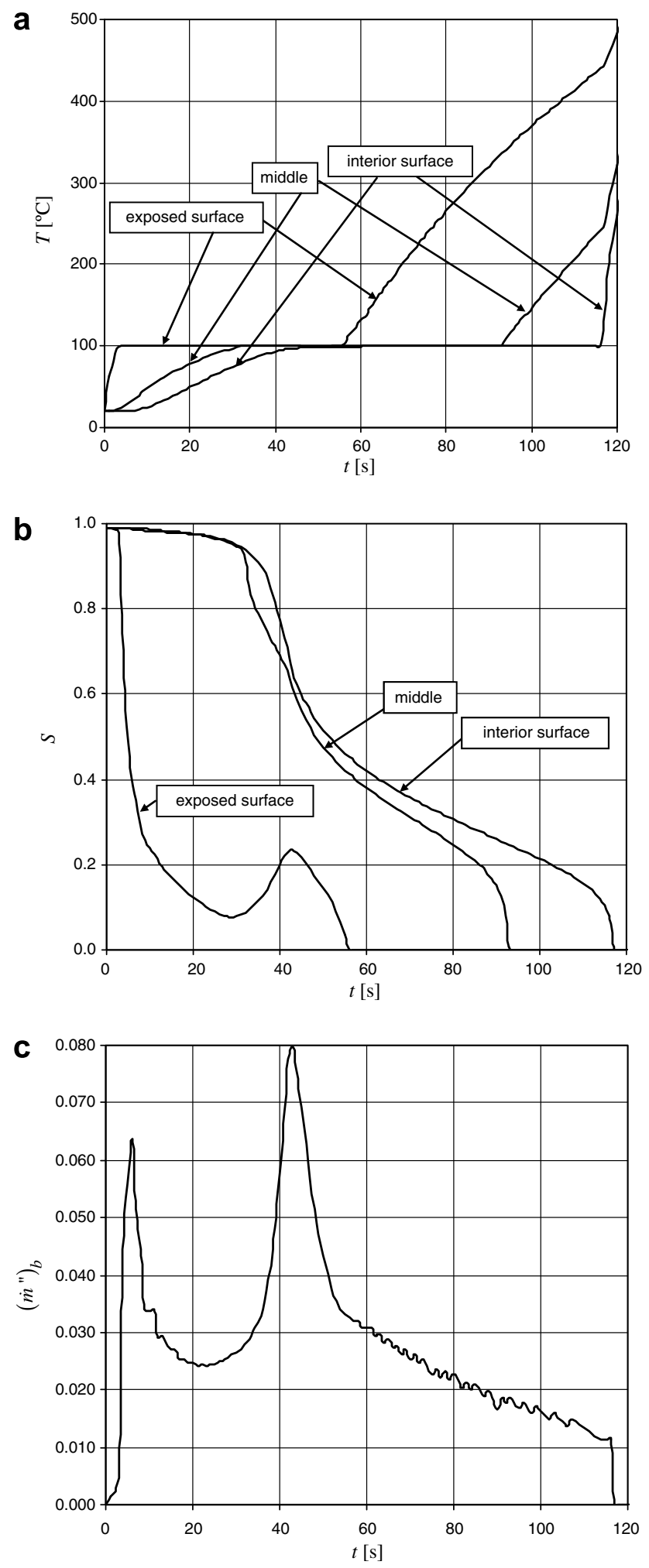

Fig. 4. Time evolution of results for $f_{\sigma}=0.04$ : (a) temperature at the exposed surface, at the middle and at the interior surface of the porous medium; (b) saturation at the exposed surface, at the middle and at the interior surface of the porous medium; and (c) water mass flux at the exposed surface, in $\mathrm{kg} /\left(\mathrm{m}^{2} \mathrm{~s}\right)$.

the exposed surface can reach considerably small values of saturation, and after massive vaporization takes place at the interior of the porous medium a regain of liquid water occurs at the neighboring of the exposed surface. This can be seen when examining the time evolution of the saturation at the exposed surface, in Fig. 4b. Water moves from the interior towards the surface by diffusion (vapor) and convection (liquid, including the capillarity effects, and vapor). Heat is transferred from the exposed surface towards the interior by conduction and radiation, and the obtained results are thus a consequence of the combination of all these different heat and mass transfer mechanisms. Once the exposed surface remains dry, phase change takes place at the interior only and water vapor is transferred from the interior towards the exposed surface by convection and diffusion. It is to be noted that there is a counterflow process: heat is transferred by conduction and radiation towards the interior of the porous medium, while the main enthalpy flow, associated with the vapor flow, takes place in the opposite direction, from the interior towards the surface. This process is important to maintain the exposed surface temperature within contained values, as it is continuously swept by water vapor coming from the vaporization that occurs inside the porous medium. Saturation at the interior surface closely follows the saturation at the middle of the porous medium, the saturation of the interior surface being always higher than the saturation at the middle. For any of the considered positions, decrease in saturation is very steep as its value approaches zero.

Fig. $4 \mathrm{c}$ shows the time evolution of the mass flux that leaves the porous medium. It is not constant, and it is strongly conditioned by the aforementioned heat and mass transfer mechanisms. Initially, mass flux is low, as there is no vaporization nor at the exposed surface nor at the interior of the porous medium. After that, the steep decrease of saturation at the exposed surface is associated with a high water outflow at the surface, some of it being composed of liquid water. When vaporization occurs at the interior, vapor flows towards the exposed surface and a liquid water regain occurs in the neighboring of the exposed surface. This process is accompanied of a reduction on the flux of water leaving the porous medium. Once finished this period of liquid water regain, water flux is directed towards the exposed surface, what corresponds to a high value of the water mass outflow. When liquid water becomes absent from the exposed surface, the water outflow decreases, and it decreases with the distance between the vaporization location and the exposed surface. As the numerical solution has a discrete nature, the decrease of the water outflow is not a monotonic function of time. At any particular control volume there is a heating process, a vaporization process, and a vapor flow process. When liquid water no more exists in a control volume, the vaporization process starts at the next control volume towards the interior of the porous medium. The water flow rate is initially high, but it decreases with time, as the saturation level deceases. This discrete nature of the numerical solution can be seen in Fig. 4c. When no more liquid water exists inside the overall porous medium, the water outflow steeply decreases to zero. 
a
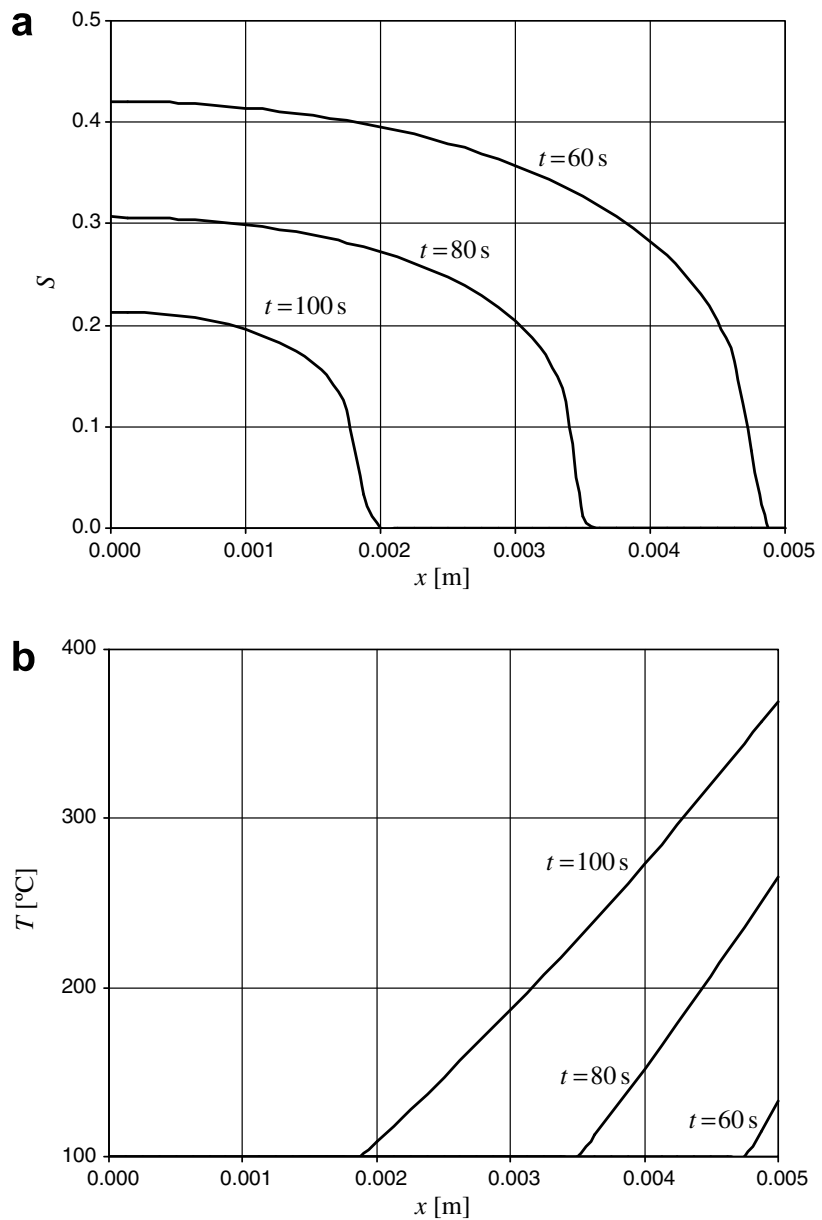

Fig. 5. Space evolution of saturation (a) and temperature (b) fields for $f_{\sigma}=0.04$, for time exposures $t=60 \mathrm{~s}, t=80 \mathrm{~s}$, and $t=100 \mathrm{~s}$.

A picture about what happens inside the porous medium as the exposition takes place can be seen in Fig. 5 once again for the case of $f_{\sigma}=0.04$. For an exposition time of $60 \mathrm{~s}$, it can be seen that the saturation levels are very small at the exposed surface and nearly constant at the remaining thickness of the porous medium, and that temperature is considerably high at the exposed surface and essentially uniform and equal to $100^{\circ} \mathrm{C}$ at the remaining of the porous medium. The highest space temperature differences occur where saturation values are extremely low. The vaporization front corresponds to the change between a region where $S=0$ and a region where $S>0$, and temperature is $T \approx 100{ }^{\circ} \mathrm{C}$ (due to the high permeability of the porous medium) at the vaporization front and $T>100{ }^{\circ} \mathrm{C}$ where $S=0$. As the time of exposure increases, the vaporization front moves towards the interior of the porous medium, as it can be seen in Fig. 5a for $t=80 \mathrm{~s}$. The aforementioned characteristics of the vaporization front in terms of saturation and temperature remain no matter what is the particular location of the vaporization front. For a long time exposure, $t=100 \mathrm{~s}$, the saturation and temperature fields in the thermal barrier are also presented in Fig. 5.

Results similar to the aforementioned ones in Fig. 4, now for $f_{\sigma}=0.1$, are presented in Fig. 6 . The main patterns
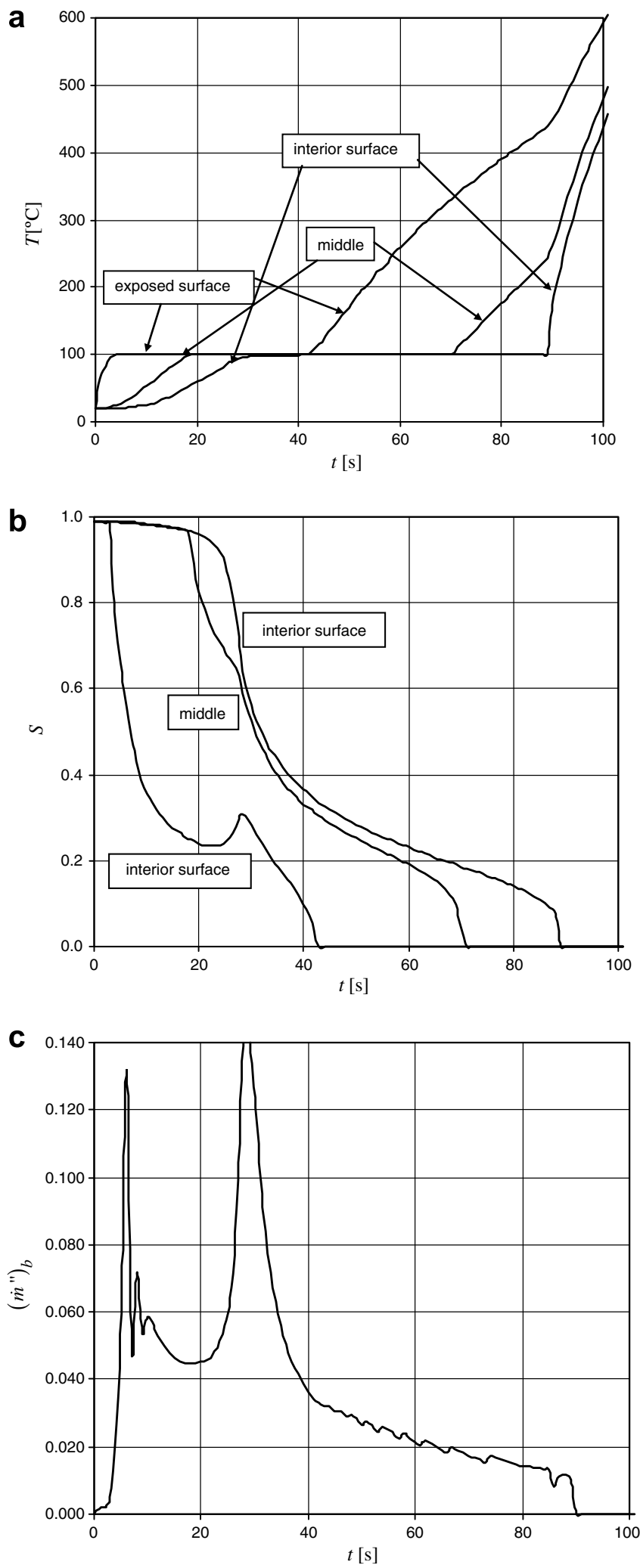

Fig. 6. Time evolution of results for $f_{\sigma}=0.1$ : (a) temperature at the exposed surface, at the middle and at the interior surface of the porous medium; (b) saturation at the exposed surface, at the middle and at the interior surface of the porous medium; and (c) water mass flux at the exposed surface, in $\mathrm{kg} /\left(\mathrm{m}^{2} \mathrm{~s}\right)$. 
remain unchanged, but the process is accelerated, as the capillary effect is more intense in this case. From Fig. 6a it is observed that the exposed surface remains dry closely $40 \mathrm{~s}$ after the beginning of the exposition, the middle of the porous medium remains dry closely $70 \mathrm{~s}$ after the beginning of the exposition, and the thermal barrier has an active role during closely $90 \mathrm{~s}$, the instant after which liquid water is absent from the porous medium. In what concerns the saturation evolution with time, patterns of Fig. $6 \mathrm{~b}$ are very similar to those present in Fig. 4b, exception made to the fact that the overall process is accelerated in the former due to the major relevance of the capillary effects. The water outflux at the exposed surface is depicted in Fig. 6c. When compared with Fig. 4c, it is observed that the outflux values are considerably higher for $f_{\sigma}=0.1$ than for $f_{\sigma}=0.04$. In this way, it is concluded that the capillary effects need to be taken into account in a careful way when dealing with porous media with high permeabilities. It is to be retained, however, that when the vaporization front travels over the most interior parts of the porous medium the water outflux is similar in both cases of $f_{\sigma}=0.04$ and $f_{\sigma}=0.1$. Physically, this is due to the fact that, in this case, the resulting mass transfer intensity is only weakly depen-
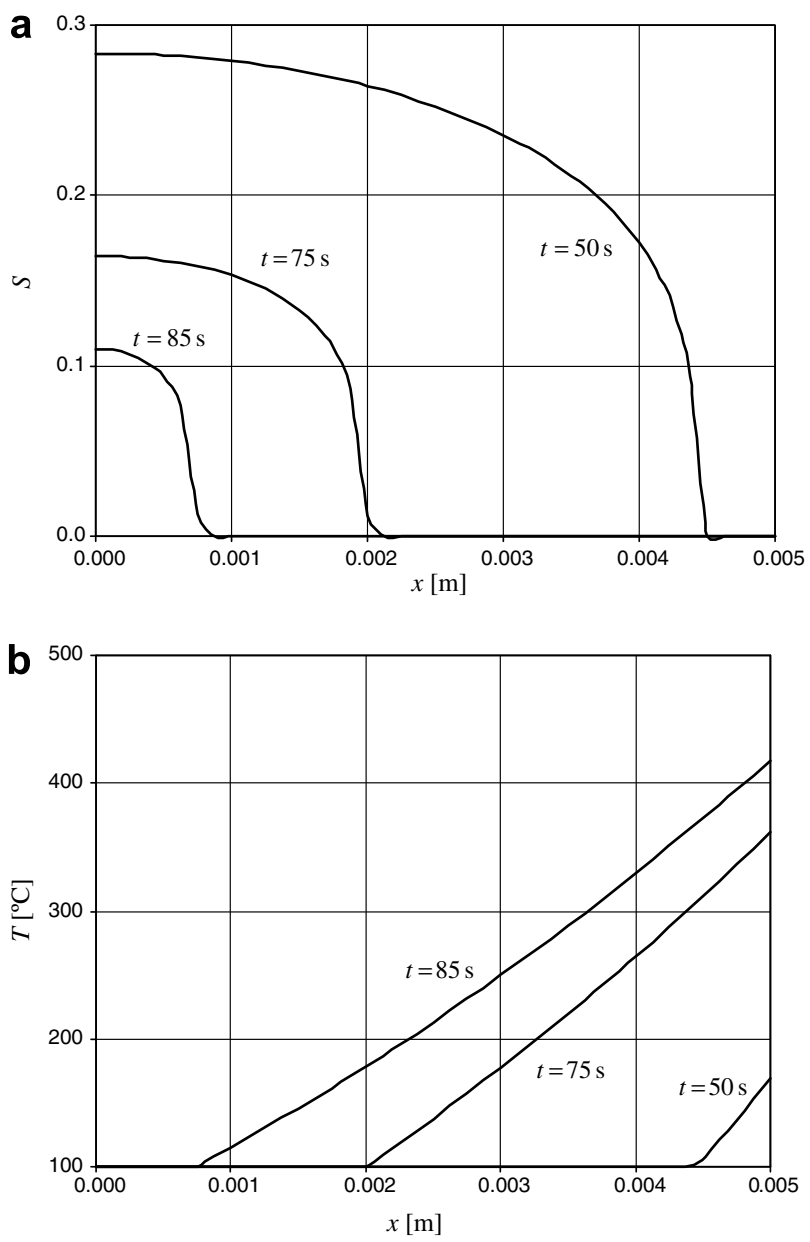

Fig. 7. Space evolution of saturation (a) and temperature (b) fields for $f_{\sigma}=0.1$, for time exposures $t=50 \mathrm{~s}, t=75 \mathrm{~s}$, and $t=85 \mathrm{~s}$. dent on the capillary effects. In this case, the main mechanisms for water vapor mass transfer are convection (due to the pressure differences of the gaseous phase) and diffusion.

The picture about the saturation and temperature evolution with time for $f_{\sigma}=0.1$ is depicted in Fig. 7. In this case, it is observed that for an exposure time of $50 \mathrm{~s}$ no more liquid water exists at the exposed surface, which is dried, and that temperature is increasing at that surface. Comparing with results for $f_{\sigma}=0.04$, it is obtained that more water was expulsed at the initial stages of exposure in the present case. For a time exposure of $75 \mathrm{~s}$ liquid water is absent in more than one half of the porous medium, and considerably high temperature gradients are observed in the dried zone. For the situation close to the end of the action of the thermal barrier, for $t=85 \mathrm{~s}$, almost all the porous medium is dried, and a strong temperature difference exists between the exposed surface and the interior surface.

Comparing results obtained for $f_{\sigma}=0.04$ and for $f_{\sigma}=0.1$, it can be concluded that the way as the capillarity effects are considered has strong influence on the liquid water transfer in the initial times of exposure, and thus on the water outflow rate and on the time during which liquid water exists in the porous medium and it behaves as a thermal barrier. Due to that, care needs to be taken when using the Leverett function to evaluate the capillary depression for porous media with a considerably high permeability.

\section{Conclusions}

Modeling and simulation of thermal barriers consisting of highly humid porous media is a challenging task. Physical model needs to take into account the heat transfer mechanisms, including radiation heat transfer and phase change, the latter being the main reason that justifies the use the highly humid porous media as thermal barriers. Different approaches can be made to the radiation heat transfer taking place in the thermal barriers. In this work a simplified radiation model was used, that has proven its potential when used in firefighter cloths modeling. Mass transfer occurs both in the liquid and vapor phases, each transfer phenomenon being described by different transfer laws, involving different information (thermophysical properties, permeability, porosity, etc.) of the involved media.

Once the physical model established, special attention needs to be given to the used boundary conditions. It is usual, in the drying literature as well as in the literature dealing with the behavior of concrete or other materials subjected to high temperatures, to consider the convective mass transfer mechanism between the exposed surface and the environment, through a specified convection transfer coefficient. However, for the case of thermal barriers, where the vaporization process takes place inside the porous medium, the mass transfer rate from the thermal barrier to the environment is controlled by the vaporization process and vapor effusion, and not by the convection mechanism. For thermal barriers including a perforated 
radiation shield, as in the present case, this is the physically realistic mass flow boundary condition. In order to model this kind of mass flow boundary condition, velocity of the liquid and gaseous phases must be carefully evaluated at the boundary, with implications on the mesh grid that needs to be considered. These aspects were detailed in the body of the present work.

Numerical implementation of the physical model needs to take into account some special points. The moisture content of the gaseous phase can be obtained from the solution of the water mass conservation equation, in the case of null local saturation, or from the saturation equation in the case of non-zero local saturation, under the assumption that locally vapor is in saturation conditions. In this way, water mass conservation equation can be used to evaluate two different variables, depending on the local value of saturation, what is an unusual practice. The presented methodology applies assuming that the gaseous phase is always present, the completely saturated porous medium being taken as with a saturation of 0.99 . Once obtained the discretized equations, care needs to be taken in order to solve them. Due to the highly non-linear character of the involved equations, and to the fact that they are strongly linked, segregated methods are not the most adequate ones and a method to solve non-linear equations needs to be used. As these methods need the inversion of the Jacobian matrix, care needs to be devoted to the fact that the water mass conservation equation can be used to evaluate two different dependent variables, depending on the local value of saturation.

Real conditions of exposure lead to extremely high heat fluxes and vaporization rates. Successful simulations can be conducted only if care is taken with the involved numerical model and space and time meshes, as small changes on the involved parameters can make the difference between success and failure.

Physical model involves a set of information depending on the involved media. Some illustrative results were presented for some particular involved media, showing the potential of the highly humid porous media when used as thermal barriers. These results also show the potential of the presented numerical methodology to deal with the complex physical model describing this kind of systems. Even if the present work deals with the modeling and simulation of thermal barriers, the main aspects apply equally to other similar heat and mass transfer systems.

\section{References}

[1] S. Muruyama, R. Viskanta, T. Aihara, Analysis of an active high temperature thermal insulation system, Int. J. Heat Fluid Flow 11 (3) (1990) 196-203.

[2] S. Muruyama, T. Aihara, R. Viskanta, Transient behavior of an active thermal protection system, Int. J. Heat Mass Transfer 34 (3) (1991) 625-632.

[3] J. Bellettre, F. Bataille, A. Lallemande, Prediction of thermal protection of walls by blowing with different fluids, Int. J. Therm. Sci. 38 (1999) 492-500.
[4] P. Chitrphiromsri, A. Kuznetsov, Modeling heat and mass transport in firefighter protective clothing during flash fire exposure, Heat Mass Transfer 41 (2005) 206-215.

[5] J.J. Barry, R.W. Hill, Computational modeling of protective clothing, Int. Nonwovens J. 12 (3) (2003) 25-34.

[6] R.W. Hill, J.J. Barry, New developments in the assessment of protective fabrics using computational methods, Int. Nonwovens J. 13 (4) (2004) 22-30.

[7] W.E. Mell, J.R. Lawson, A heat transfer model for fire fighters' protective clothing, National Institute of Standards and Technology Report NISTIR/6299, 1999.

[8] W.E. Mell, J.R. Lawson, A heat transfer model for fire fighters' protective clothing, Fire Technol. 36 (1) (2000) 39-68.

[9] K. Prasad, W. Twilley, J.R. Lawson, Thermal performance of firefighters' protective clothing: 1. Numerical study of transient heat and vapor transfer, National Institute of Standards and Technology Report NISTIR/6881, 2002

[10] J. Barry, R. Hill, P. Brasser, M. Sobera, C. Kleijn, P. Gibson, Computational fluid dynamics modeling of fabric systems for intelligent garment design, Mater. Res. Soc. Bull. 28 (8) (2003) 568573.

[11] G. Havenith, Individualized model of human thermoregulation for the simulation of heat stress response, J. Appl. Physiol. 90 (2001) 1943-1954.

[12] C.F. Boyd, M. Di Marzo, The behavior of a fire protection foam exposed to radiant heating, Int. J. Heat Mass Transfer 41 (12) (1998) 1719-1728.

[13] A.M. Papadopoulos, State of the art in thermal insulation materials and aims for future developments, Energy Build. 37 (2005) 7786.

[14] C.N. Ang, Y.C. Yang, The effect of water movement on specific heat of gypsum plasterboard in heat transfer analysis under natural fire exposure, Construct. Build. Mater. 18 (2004) 505-515.

[15] M.R.E. Looyeh, P. Bettess, A finite element model for the fireperformance of GRP panels including variable thermal properties, Finite Elem. Anal. Des. 30 (1998) 313-324.

[16] D.A. Torvi, J.D. Dale, Heat transfer in thin fibrous materials under high heat flux, Fire Technol. 35 (3) (1999) 210-231.

[17] Z.-F. Jin, Y. Asako, Y. Yamaguchi, M. Harada, Fire resistance test for fire protection materials with higher water content, Int. J. Heat Mass Transfer 43 (2000) 4395-4404.

[18] Y. Ychikawa, G.L. England, Prediction of moisture migration and pore pressure build-up in concrete at high temperatures, Nucl. Eng. Des. 228 (2004) 245-259.

[19] A.P. Kuryachii, Modeling of heat and mass transfer in systems of radiation-evaporation thermal protection, J. Eng. Phys. Thermophys. 74 (6) (2001) 1412-1425.

[20] R.T. Tenchev, L.Y. Li, J.A. Purkiss, Finite element analysis of coupled heat and moisture transfer in concrete subjected to fire, Numer. Heat Transfer, Part A 39 (2001) 685-710.

[21] J. Selih, A.C.M. Sousa, T.W. Bremner, Moisture transport in initially saturated concrete during drying, Transp. Porous Med. 24 (1996) 81106.

[22] R.K.K. Yuen, W.K. Kwok, S.M. Lo, A mathematical model for heat and mass transfer in concrete at elevated temperature due to fires, in: G. De Vahl Davis, E. Leonardi (Eds.), Third International Symposium on Advances in Computational Heat Transfer (CHT-04), 2004, Kirkenes-Bergen (Norway), Paper 232, Begell House, New York, 2004.

[23] D. Gawin, C.E. Majorana, B.A. Schrefler, Numerical analysis of hygro-thermal behavior and damage of concrete at high temperature, Mech. Cohes.-Frict. Mater. 4 (1999) 37-74.

[24] D. Gawin, E. Pesavento, B.A. Schrefler, Modelling of hygro-thermal behavior and damage of concrete at temperature above the critical point of water, Int. J. Numer. Anal. Meth. Geomech. 26 (2002) 537 562.

[25] G.A. Khoury, Effect of fire on concrete and concrete structures, Prog. Struct. Eng. Mater. 2 (2000) 429-447. 
[26] M.S. Sahota, P.J. Pagni, Heat and mass transfer in porous media subject to fires, Int. J. Heat Mass Transfer 22 (1979) 1069-1081.

[27] J. Fan, X. Wen, Modeling heat and moisture transfer through fibrous insulation with phase change and mobile condensates, Int. J. Heat Mass Transfer 45 (2002) 4045-4055.

[28] K. Daryabeigi, Heat transfer in high-temperature fibrous insulation, in: Proc. of the 8th AIAA/ASME Joint Thermophysics and Heat Transfer Conference, AIAA 2002-3332, 24-26 June 2002, St. Louis, MO, 2002.

[29] I. Goldfarb, A. Zinoviev, A study of delayed spontaneous insulation fires, Phys. Lett. A 311 (2003) 491-500.

[30] K. Pruess, C. Calore, R. Celati, Y.S. Wu, An analytical solution of heat transfer at a boiling front moving through a porous medium, Int. J. Heat Mass Transfer 30 (12) (1987) 2595-2602.

[31] P.S. Ramesh, K. Torrance, Stability of boiling in porous media, Int. J. Heat Mass Transfer 33 (9) (1990) 1895-1990.

[32] C.Y. Yang, A fixed-grid numerical algorithm for two-phase flow and heat transfer in porous media, Numer. Heat Transfer, Part B 31 (1997) 85-105.

[33] M. Najjiari, S. Ben Nashrallah, Numerical study of boiling with mixed convection in a vertical porous layer, Int. J. Therm. Sci. 41 (2002) 913-925.

[34] J. Bénard, R. Eymard, X. Nicolas, C. Chavant, Boiling in porous media: model and simulations, Transp. Porous Med. 60 (1) (2005) 131.

[35] D.A. Nield, A. Bejan, Convection in Porous Media, second ed., Springer, New York, 1999.

[36] M. Kaviany, Principles of Heat Transfer in Porous Media, second ed., Springer, New York, 1995.
[37] S. Ben Nasrallah, P. Perré, Detailed study of a model of heat and mass transfer during convective drying of porous media, Int. J. Heat Mass Transfer 31 (1988) 957-967.

[38] P. Perré, A. DeGiovanni, Simulation par volumes finis des transferts couplés en milieux poreux anisotropes: séchage du bois à basse et à haute température, Int. J. Heat Mass Transfer 33 (1990) 2463-2478.

[39] P. Perré, I.W. Turner, A 3D version of Transpore: A comprehensive heat and mass transfer computational model for simulating the drying of porous media, Int. J. Heat Mass Transfer 42 (1999) 4501-4521.

[40] P. Baggio, C. Bonacina, B.A. Schrefler, Some considerations on modeling heat and mass transfer in porous media, Transp. Porous Med. 28 (1997) 233-251.

[41] A.R. Figueiredo, J.J. Costa, Experimental analysis of the use of wet porous media for thermal protection against high intensive heat fluxes, Int. J. Heat Mass Transfer 47 (2004) 11-19.

[42] R.B. Bird, W.E. Stewart, E.N. Lightfoot, Transport Phenomena, second ed., Wiley, New York, 2002.

[43] V.A.F. Costa, Estudo do Processo de Secagem de Materiais Granulares em Leito Fixo (in Portuguese), M.Sc. Thesis, Departamento de Engenharia Mecânica, Universidade de Coimbra, Portugal, 1989.

[44] D.A. Torvi, Heat transfer in thin fibrous materials under high heat flux conditions, Ph.D. Thesis, University of Alberta, Edmonton, Alberta, Canada, 1997.

[45] P. Chitrphiromsri, Modeling of thermal performance of firefighter protective clothing during intense heat exposure, Ph.D. Thesis, North Carolina State University, Raleigh, NC, 2004.

[46] S.V. Patankar, Numerical Heat Transfer and Fluid Flow, Hemisphere/McGraw-Hill, Washington, DC, 1980. 